\title{
UrbanisMo EN LA MARCA ORIENTAL DE AL-ANDALUS DURANTE EL CALIFATO (940-974): EL EJEMPLO DE MADĪNA ṬURȚŪ̌̌A A TRAVÉS DE LAS FUENTES ARQUEOLÓGICAS Y ESCRITAS
}

En este texto presentaremos las principales reformas que en la ciudad de Țurțūša y su entorno más inmediato se llevaron a cabo durante las décadas centrales del s. X. Entendemos, a partir del estudio de las fuentes escritas, que el período comprendido entre los años 940 y 974 supusieron un lapso de relativa estabilidad a ambos lados de la frontera entre al-Andalus y los condados catalanes. Es, por tanto, durante este momento cuando situamos una especialmente remarcable actividad por parte del Estado, a través de los gobernadores de la ciudad, de refuerzo de las estructuras defensivas y arquitectónicas dentro del ámbito urbano y periurbano. Analizaremos, entre otros, los casos de las murallas o el arsenal a nivel militar y la mezquita aljama o los baños en cuanto a obra civil, con el objetivo de presentar un esquema del importante programa de transformaciones al que la ciudad se vio abocada tras la instauración del Califato.

Palabras clave: Tortosa, califato, mezquita, arsenal, atarazana, baños.

\section{Urbanism in the Eastern March of Al-Andalus During the Caliphate (940-974): the Example of Madīna Ṭurțūša through ArChaEological ANd Written Sources}

This text focuses on the main refurbishments accomplished in the city of Țurțūsa and its surroundings during the central decades of the 10th century. This cycle, which covers from 940 to 974, is thought to be a calmed period within the hostilities between Muslims and Christians, as regarded by written sources. Therefore, both the Caliph and the Count of Barcelona took advantage of this situation in order to reinforce their defensive, architectonic and urban structures. In this way, we have analysed several case studies, both in military and civil constructions, presenting finally a synthesis about the transformations of the city after the establishment of the Caliphate.

Key words: Tortosa, Caliphate, mosque, arsenal, dockyard, bath house.

En este texto se sintetizan las principales transformaciones llevadas a cabo en la edilicia pública, tanto civil como militar, de la ciudad de Țurțūša (Tortosa) y su entorno durante el período de paz sostenido entre al-Andalus y los condados catalanes en las décadas centrales del s. $X$. Esta situación fue aprovechada a ambos lados de la frontera para fortalecer sus posiciones avanzadas y, en el caso andalusí, acometer un proceso de reforma urbana que en la ciudad de Tortosa alcanzó una importante intensidad. La intención de este artículo, por tanto, va encaminada a analizar estos cambios a través de los hallazgos arqueológicos aparecidos durante las últimas décadas en esta ciudad así como a contrastarlos con las informaciones provenientes de las fuentes escritas, tanto árabes como latinas. Sin ninguna intención de convertir este texto en una solución definitiva a esta cuestión, se presentan 
algunos casos de estudio que son representativos de esta dinámica, como la construcción o las reformas llevadas a cabo en la mezquita aljama, el arsenal, los baños o en una fortificación satélite de la ciudad como es el hisn de Amposta. En definitiva, se espera sintetizar el proceso de transformación urbana y periurbana desarrollado en esta importante ciudad de la Marca Oriental, una circunscripción militar y administrativa creada justo en este momento para reforzar la organización fronteriza de este sector de al-Andalus.

\section{CONCRECIÓN TERRITORIAL E HISTÓRICA}

El área donde se ha desarrollado este estudio comprende las actuales comarcas meridionales catalanas del Montsià y del Baix Ebre (Tarragona), las cuales muestran una correspondencia precisa con los límites establecidos por la carta de población de la ciudad de Tortosa de 1149 (CPFC: 75). Situada en el centro de este territorio, esta ciudad controla el curso inferior del río Ebro y el extenso llano aluvial formado en este tramo hasta su desembocadura. Con abundantes hallazgos arqueológicos dentro del marco urbano desde época ibérica, las limitaciones a la expansión de la ciudad, con el río a poniente y las estribaciones montañosas de la Serra del Boix a levante, resultan obvias. Esta situación ha comportado una amplia superposición de estratos históricos que dificultan en gran medida la lectura arqueológica de sus transformaciones urbanas, aún más compleja si tenemos en cuenta los elevados niveles freáticos de las zonas más cercanas al río. Aun así, diferentes iniciativas de investigación durante los años 80 (Curto et al. 1986) y más recientemente con un proyecto específico de estudio de la evolución urbana de la ciudad han permitido obtener importantes resultados (Diloli et al. 2008).

Históricamente, centraremos nuestra atención en el período comprendido entre la intitulación califal de 'Abd al-Raḥmān al-Nāṣir (929) y el ascenso de facto al poder de la dinastía amirí (978). Con este hito inicial al-Andalus se desligaba religiosamente del califato abasí de Bagdad y el nuevo califa recibía una legitimación completa para continuar el proceso de pacificación y control de todos los territorios peninsulares sujetos a control de Córdoba. Aprovechando el potencial militar de su ejército y tras la derrota de gran parte de las dinastías fronterizas opositoras, como la tuyibí en la Marca Superior, el califa pudo concretar su dominio político sobre los condados catalanes a través de diversos tratados de sumisión sucesivos. Al primero de ellos, firmado el verano del año 940 en la ciudad de Barcelona entre el conde Sunyer y el secretario (kātib) de 'Abd al-Raḥmān al-Nāṣir, se sometieron también muchos de los señores ( ${ }^{c} u z a m \bar{a}^{\top}$ ) y reyes (mulūk) que habían acudido a la confirmación de la paz (Ibn Hayyān: 308-309). Confirmada nuevamente esta tregua el año siguiente por parte de Sendred, vicario y mensajero del conde de Barcelona (Ibn Hayyān: 317), se llega incluso a tener noticias de la llamada del califa a los reyes francos (mulūk al-Faranŷa) adscritos a su paz y obediencia para participar en las algaras bajo su estandarte (Ibn Hayyān: 319). Parece que esta relación debió mantenerse relativamente estable durante los años posteriores al

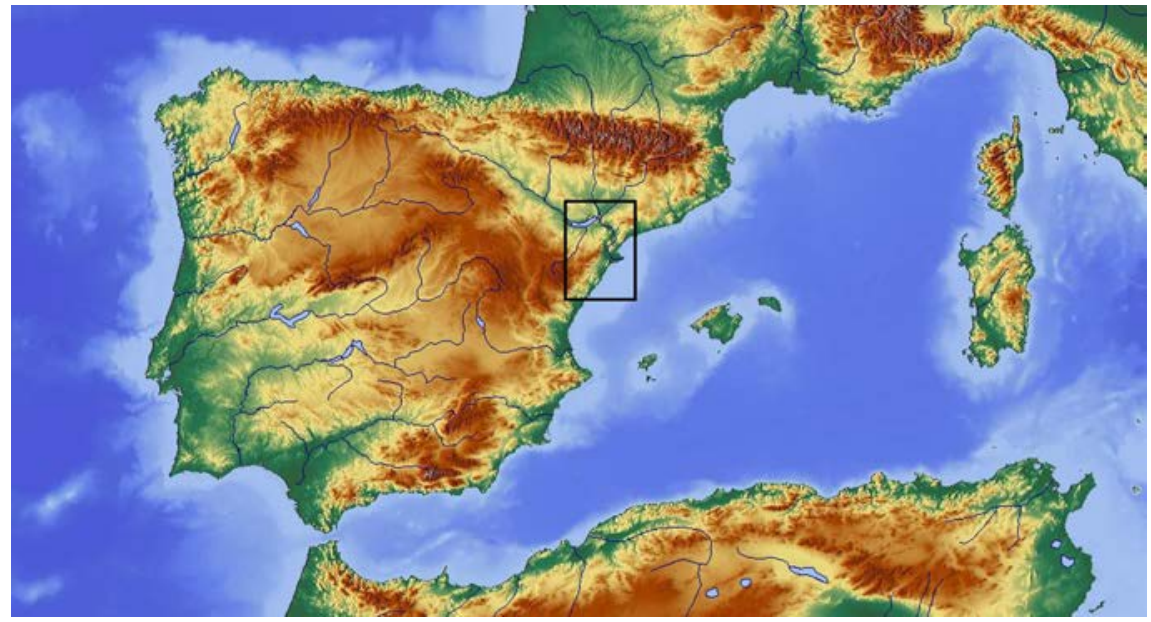

Fig. 1. Situación del área de estudio en el contexto mediterráneo. 
tratado, durante los cuales no se recogen noticias de ataques mutuos y se tiene constancia de embajadas periódicas para confirmar los acuerdos de paz (Ibn Jaldūn: IV, 143).

Con la llegada al poder de al-Ḥakam al-Mustanșir las tensiones se retomaron nuevamente con algunos enfrentamientos entre los ejércitos califales y condales en Almería y Tortosa, durante el verano de 964 (Ibn al-Jațīb: I, 478-479). Aun así todo indica que, a consecuencia de las fallidas expediciones catalanas, tan solo dos años después los condes Borrell y Miró habrían enviado emisarios para renovar la paz con el califa (Ibn Jaldūn: IV, 145). Se trata nuevamente de una sumisión que parece haberse mantenido efectiva hasta el final del gobierno de al-Mustanșir, renovándose nuevamente en 971 (Ibn Hayyān 2: 20-23) y 974 (Ibn Hayyān 2: 167-168). A pesar de ello, esta última confirmación no debió durar mucho, pues con la llegada de los amiríes al poder, de facto en 976, el conflicto entre ambos bloques se recrudeció (Ibn Jaldūn: I, Ap.: 22-23).

Esta situación de paz intermitente mantenida aproximadamente entre los años 940 y 974 fue aprovechada, tanto por cristianos como por musulmanes, para reforzar sus respectivas posiciones. En el primer caso se puede observar a través de la intensificación del proceso de encastillamiento de los territorios de la Catalunya Central (Gibert 2011: 429-447) y de la Marca del Penedés (Martí 1992: 28-35), que ya se había iniciado décadas antes en los territorios más septentrionales de los condados. Por otro lado, en cuanto a las iniciativas andalusíes, se intuyen dos grandes grupos de cambios impulsados por el califa: uno a nivel administrativo que afectaría al distrito o provincia controlada por la ciudad y otro basado en una serie de reformas defensivas y arquitectónicas en áreas urbanas y periurbanas, encaminadas a reforzar la frontera y en especial el sector de Tortosa.

En cuanto al primer bloque, podemos destacar entre otros factores la creación de una demarcación fronteriza propia para este territorio, conocida como al-Tagr alŠarqī (Manzano 1991: 54), la supervisión de la cual fue asignada a Muḥammad b. 'Abd Allāh b. Abī 'Īsà en el año 940 (Ibn Hayyān: 307-308). Tan solo dos años después, el califa decidió también establecer una nueva institución, la Supervisión General de las Fronteras, con el objetivo de ejercer un mayor control sobre los jueces y gobernadores de este territorio, así como vigilar la llegada de cualquier personaje procedente del país de los francos (Ibn Ḥayyān: 329). El primer encargado de esta supervisión fue Mundir b. Sa'īd al-Ballūțī, que ya había ejercido el cargo de cadí de la Marca Oriental con anterioridad (Ibn al-Abbār: 792), por lo que sabemos que el establecimiento de esta circunscripción puede retrotraerse aún con anterioridad al 940. Parece, por tanto, que la ciudad de Tortosa ganó un especial protagonismo en este momento como centro fronterizo de primer orden, a la cabeza de una amplia jurisdicción territorial que debía coincidir con los límites de su provincia (madīna) en época emiral, desde tierras castellonenses hasta la confluencia del río Segre con el Ebro.

Esta importante tarea desarrollada recibió el interés de la capital cordobesa ayudando, junto con la situación de paz fronteriza, a iniciar una reorganización territorial de gran envergadura. Así, es durante este período cuando aparecen las primeras iniciativas de construcción de la mayor parte de los hușūn del territorio tortosino, así como la delimitación de unas circunscripciones administrativas vinculadas a estos centros fortificados (Negre 2013: 558-562). Las funciones de estos enclaves de ámbito territorial estarían relacionadas principalmente con el control de las vías de comunicación, la recaudación de tributos y al mantenimiento de guarniciones destinadas a la defensa del territorio, con especial atención a las incursiones costeras. Resulta de gran importancia este último elemento, pues muchos de los ataques contra los territorios andalusíes habían llegado desde el mar. Estas incursiones, junto con las también constantes por vía terrestre, llevaron además a los habitantes de este territorio a solicitar al califa una menor presión de las contribuciones al erario público, a lo que éste respondió levantando algunas de las percepciones coránicas (al-zakawāt wa l-șadaqāț), tal y como dejó establecido por escrito (Ibn Hayyān: 316). Centrémonos ahora en el objeto preferente de este texto, es decir, en el segundo bloque de actuaciones, de carácter defensivo y arquitectónico, vinculadas al ámbito urbano y periurbano de Tortosa.

\section{REFORMAS DEFENSIVAS URBANAS: MURALLAS, ALCAZABA Y ARSENAL}

El dominio andalusí aún alcanzaba los confines del Penedés y del río Llobregat a inicios del s. X, siendo Olèrdola su principal fortificación avanzada, hasta que la ofensiva condal conquistó este sector y trasladó la frontera hasta el entorno de Tarragona, consolidando a partir de entonces una densa red de castillos en la zona ocupada (Martí 1992: 28-35; Gibert 2011: 429-447). Esta es la 


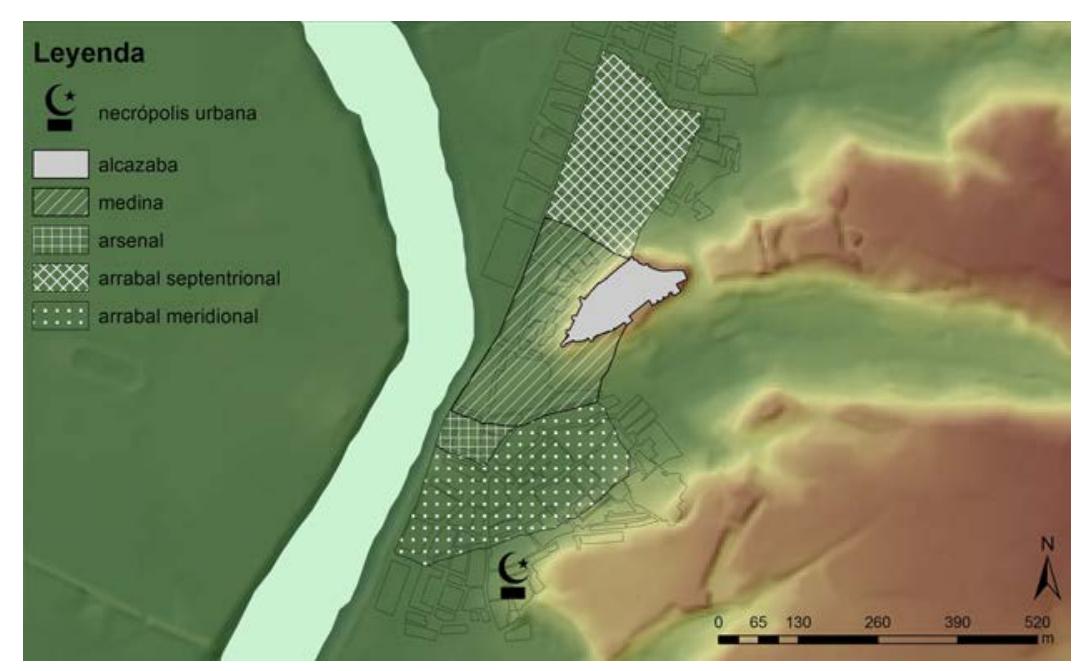

Fig. 2. Representación hipotética de la planta de Tortosa en época califal.

nueva línea divisoria que se sanciona hacia el año 940, cuando el califa de Córdoba y el conde de Barcelona resuelven un tratado de paz que, con pequeñas intermitencias, perdurará hasta el último cuarto del $\mathrm{s}$. X, tal y como hemos visto. Es en este contexto que la ciudad de Tortosa parece conocer su mayor apogeo, si bien las reformas a las que se vio abocada a nivel defensivo fueron amplias y extensas.

En primer lugar, cabe destacar que, después de diversos siglos aprovechando las murallas defensivas de la ciudad levantadas durante la Antigüedad, las fuentes escritas nos describen la construcción de un poderoso recinto por orden de 'Abd al-Raḥmān b. al-Naẓāām. Fue este personaje, designado gobernador de la ciudad en el año 940 en sustitución de Aḥmad b. Sa'īd b. Mālik (Ibn Hayyān: 314), uno de los principales promotores de las reformas llevadas a cabo en Tortosa. Estas mismas fuentes son confusas respecto al alcance de estos muros aunque, atendiendo a la indicación clara que hacen respecto a que reseguían el trazado antiguo, se considera que debían limitarse al área de la medina primitiva de la ciudad (aproximadamente calle de Taules Velles al sur y de la Cortadura al norte), fusionándola entonces con la qașaba superior, la Suda.

Arqueológicamente, en la calle Cruera se ha podido detectar una parte del levantamiento de la muralla andalusí, formada por una estructura de piedras irregulares ligadas con mortero de cal y atribuida por los arqueólogos al s. X (Diloli et al. 2008: 160). No obstante, por su disposición perpendicular al trazado del río y de la fachada fluvial, así como por el uso de piedra no trabajada y ligada con cal, creemos que se debería asociar este elemento con una estructura complementaria de la muralla o con un sobre-levantamiento -contemporáneo o ligeramente posterior- de la misma, considerando que la muralla califal mantendría el uso de sillares bien escuadrados, tal y como se aprecia en la gran mayoría de las murallas andalusíes de este período en el NE peninsular (Sénac 2010; Loriente et al. 1997). Es probable que los restos de un muro de grandes dimensiones detectados durante la excavación de un solar en la calle de la Ciutat y que presentaba continuidad hacia el interior del casco urbano pudiesen formar parte de estas murallas. A pesar de esta lectura, los niveles de sedimentación sitúan los posibles cimientos de esta área más cercana al río entre 4 y $6 \mathrm{~m}$ de profundidad y muy afectados por el alto nivel de la capa freática, por lo que resulta extremadamente difícil la recuperación de los niveles más antiguos (Barraseta y Casanovas 1988: 212). El descubrimiento de diversas zonas de necrópolis tardo-antiguas en la calle de Sant Felip Neri y de la Mercè (Diloli et al. 2012) parecen también confirmar este trazado meridional que seguiría, aproximadamente, las calles de Taules Velles y Costa del Castell, donde se situaría el acceso principal a la ciudad a través de un ramal de la Via Augusta (Negre 2013b: 214).

En cuanto a la Suda, se atribuye la fundación de la ciudadela fortificada a una obra de época islámica, a pesar de los restos antiguos localizados en el mismo altiplano, a partir de la noticia de al-Himyarī en que describe con claridad la imponente alcazaba de la ciudad (AlHimyarī: 151-153). La fuente principal de de esta información se atribuye a la perdida descripción de al-Andalus 
redactada por Aḥmad b. Muhammad b. Mūsà al-Rāzī durante la primera mitad del s. X y reconstruida por E. Lévi-Provençal a partir de textos árabes y de crónicas bajomedievales castellanas y portuguesas.

Así, se considera que aunque la fortificación habría estado en funcionamiento ya durante la primera mitad del s. $\mathrm{X}$, sería durante este período de reformas posterior cuando se habría integrado completamente en el perímetro amurallado de la ciudad. A pesar de las importantes reformas que esta fortificación ha sufrido a lo largo de los siglos, aún se pueden observar algunos tramos de la muralla en la cara noroccidental del perímetro de la alcazaba, donde una de las torres cuadradas que lo flanquean presenta unos sillares bien trabajados, trabados con argamasa y de proporciones más grandes que las modificaciones posteriores, que podrían pertenecer a su estructura primitiva (Curto 1997: 116). De las intervenciones arqueológicas llevadas a cabo en la ciudadela durante las obras de construcción del Parador Nacional instalado en su interior, uno de los elementos más singulares recuperados fue una lápida funeraria asociada a uno de los gobernadores de Tortosa. La inscripción de la misma, en cúfico florido, nos detalla el nombre del $q \bar{a} ’ i d$, al-Ŷāzin, además del año de su muerte, en 961, confirmando que este emplazamiento ya debía ser en época califal un lugar con una estructura residencial y fortificada de cierta importancia.

Aun así, el impulso de las amplias obras de fortificación llevadas a cabo en la ciudad se han de vincular, como ya hemos dicho, a la figura del gobernador 'Abd alRaḥmān b. al-Naẓzām. Fue este el principal encargado de impulsar las reformas ordenadas por el califa, entre las cuales destacaría la reparación de las murallas de la ciudad siguiendo el trazado antiguo (Ibn Hayyān: 314), una obra que habitualmente se asocia, entre otras funciones, a una finalidad propagandística, más aún en una zona fronteriza. También fue este mismo gobernador quien dirigió la construcción de uno de los elementos clave en el plan de consolidación de estas defensas urbanas: un imponente arsenal situado en el extremo meridional de la ciudad y del que aún se conserva su inscripción fundacional, que fecha la finalización de las obras en el año 944-945 (Yzquierdo 1998: 47-48). A pesar de la desaparición de este enclave por las diversas ampliaciones de la ciudad a lo largo de la Historia, las fuentes latinas medievales posteriores a la conquista aún nos describen su fisionomía. En concreto, detallan que contaba con un recinto flanqueado por 17 torres que fue cedido en 1149 a la comunidad judía con el objetivo de edificar aquí hasta 60 casas (CPFC: 76).
Tal cambio de funciones parece haber comportado su rápida desaparición, borrando incluso su localización exacta, que ciertas propuestas recientes tienden a situar en la retaguardia de la ciudad, en el barrio de Remolins (García et al. 1998). Esta hipótesis se basa en las diversas informaciones que, desde el s. XIII, nos describen la judería en la zona de Remolins, donde también se sitúa la sinagoga bajomedieval (Curto 1999). Se intuye que, no obstante, este barrio judío documentado en las fuentes escritas sería posterior al inicial establecido en las atarazanas a través de la donación condal de este espacio a la que hemos hecho referencia. El abandono de esta primera judería posterior a la conquista se habría de datar durante el segundo cuarto del s. XIII, momento en el cual encontramos indicios documentales, a través de una carta de franquicias fechada de 1228, del interés en tomar este recinto por parte de los Templarios. En este documento se cedían unos solares a 25 judíos para construir una nueva judería en la zona de levante de la Suda y lindando con el barranco del Rastre (TTE: 32), desplazando así a la comunidad hebrea fuera del emplazamiento de las antiguas atarazanas. Aunque probablemente esta iniciativa no debió cristalizar y los judíos terminaron por trasladarse a la zona bien documentada de Remolins, podemos enmarcar este texto dentro de una dinámica generalizada de compra de inmuebles y amortización generalizada de los solares de la fachada fluvial llevada a cabo durante la segunda mitad del s. XII y la siguiente centuria por diversas instituciones eclesiásticas. Destacaría, entre ellas, el

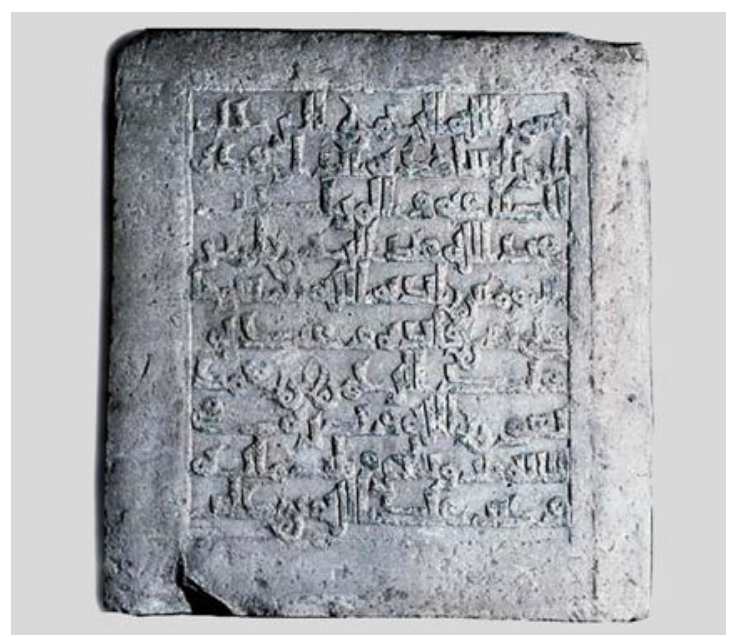

Fig. 3. Lápida fundacional del arsenal de Tortosa (Ajuntament de Tortosa, Generalitat de Catalunya). 
papel de la propia Sede Episcopal de Tortosa, que construiría en este sector la mayor parte de edificios de la Canónica bajomedieval (Almuni 2007: 406-422). Se aprecia, además, que la localización de la primitiva judería de Tortosa y, por tanto, de las atarazanas, en la zona de Remolins sería de difícil encaje, puesto que este barrio se encuentra en una importante zona de aluvión del Ebro, donde las avenidas del río pondrían en riesgo las tareas de construcción de naves.

Así, si atendemos a las fuentes escritas posteriores a la conquista, observamos que la atarazana aparece en el repartimiento verificado por el conde y los genoveses en 1149 justo después de la Villam Siccam y la Suda, formando parte del sector condal de la ciudad (civitatem cum darazana) y desvinculada por completo de la Villa de Remolins citada al inicio del documento (DCT: 18). Contra la ubicación que habitualmente se sugiere, por tanto, proponemos localizar este arsenal en el sector meridional de la ciudad donde, junto con las murallas, debió completar el plan omeya de remodelación de las defensas urbanas. En este diseño, su emplazamiento más idóneo sería previsiblemente en el entorno del Portal de la Rosa y del tramo final del barranco del Rastre, que habría actuado como foso de las defensas, todo ello en un sector bien cercano a la ubicación que el documento templario de franquicias sugería (Martí y Negre 2014: 234).

Es como mínimo un indicio verosímil de esta posibilidad que, en los grabados y planos más antiguos que se conservan de la ciudad de Tortosa, como son el de Van der Wyngaerde (1563) o el de González de Mendoza (1642), las atarazanas, así como la lonja, la alhóndiga y las dependencias portuarias se sitúen siempre en el extremo meridional de la ciudad, avanzando su posición al mismo tiempo que se desarrolla el ensanche bajomedieval hacia el barrio de los pescadores o del Temple. Es la ubicación en la que también las fuentes escritas latinas más tempranas sitúan estas instalaciones portuarias pocos años después de la conquista de Tortosa por los ejércitos feudales (DCT: 164 y 303).

Esta hipótesis sobre la situación del arsenal como bastión más avanzado a mediodía de la ciudad, cuenta con otros elementos que la apoyan, como por ejemplo algunos paralelos formales contemporáneos en otros lugares de la Península. Es el caso de las diversas fortificaciones construidas durante el Califato en el Estrecho de Gibraltar con la finalidad de controlar este importante paso marítimo ante el creciente peligro que suponía el califato fatimí. Destacamos en primer lugar, por tanto, la torre (burŷ) de Tarifa, una obra de grandes dimensiones y acabada el año 960, según su lápida fundacional. Edificada también como posición de vanguardia del establecimiento, sus características técnicas y constructivas parecen vincularla a un programa de conjunto de fortificaciones del Estrecho en el que destacarían los casos similares de Ceuta y Tánger, ambos también con fortines o arsenales avanzados (Gurriarán 2001: 179; Hita et al. 2008: 1521). La misma situación parece presentar el cada vez más bien conocido caso del arsenal de Algeciras, reconstruido por orden de 'Abd al-Raḥmān al-Nāṣir (Al-Himyarī: 9093) sobre los restos de una atarazana antigua que Ibn alQūtiyya describe al relatar el conflicto entre el ejército sirio y los beréberes en las cercanías de Ceuta en 742 (Ibn al-Qūtiyya: 12). Este fortín estaría situado también en el extremo más avanzado de la ciudad, formando parte de su perímetro amurallado, tal y como ha sido verificado recientemente a través de la excavación de sus cimientos,

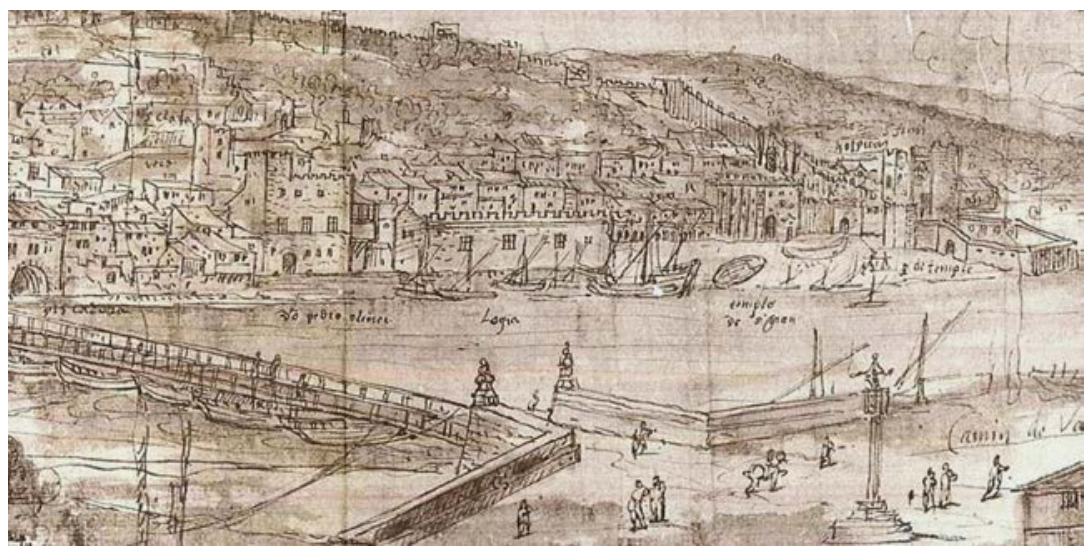

Fig. 4. Detalle del grabado de Van der Wyngaerde. 
que presentan unos muros de más de tres metros de ancho levantados con grandes sillares dispuestos a tizón (Bravo et al. 2009: 149-150).

Las técnicas constructivas, por tanto, no debieron variar en exceso para obras contemporáneas, siendo habitual el uso de sillares escuadrados ya desde el Emirato incluso en ámbitos lejanos a la capital, como puede comprobarse en casos de la Marca Superior como las murallas de Huesca, Lleida o Balaguer (Sénac 2010). Así pues, se intuye que tanto las murallas, como la alcazaba y el arsenal tortosinos también debieron haber sido construidos con un uso sistemático de sillares de grandes dimensiones y perfectamente modulados, como mínimo en sus niveles de cimentación. Es muy posible, además, que la cara exterior de estas construcciones hubiese contado también con algún tipo de almohadillado, muy habitual en las obras de la Marca Superior de este período (Gurriarán 2004). Los cercanos casos de construcciones fortificadas de obra cuadrada con sillares de grandes dimensiones y con almohadillados, como las murallas del Pla d'Almatà (Balaguer) y de Lleida, la espléndida fortificación de Castell Formós o el caso del hiṣn de Amposta que analizaremos a continuación, son ejemplos paralelos claros de este tipo de dinámicas constructivas (Giralt 1994; Loriente et al. 1997; García et al. 1998). En los ejemplos citados nos encontramos ante infraestructuras defensivas de gran envergadura, con sillares dispuestos a soga y tizón o combinando su colocación entre la cara interna y externa. Un tipo de obra alejada de la pobreza constructiva que la tradición historiográfica aún acostumbra a asociar con las ciudades andalusíes, vinculando indiscriminadamente las murallas de piedra con la época romana. Es la misma situación que encontramos también con los faros, atalayas o torres de vigilancia del s. VIII identificadas en Girona y Barcelona, donde volvemos a encontrar esta misma solución técnica durante las primeras décadas de dominio musulmán (Martí 2008).

Creemos, para finalizar, que este tipo de almohadillados que debieron presentar tanto las murallas como el arsenal de Tortosa, serían los más destacados precedentes de las diversas obras góticas de la ciudad en las que aparece esta solución nuevamente. Por ejemplo, está bien documentada su presencia en los muros exteriores de la capilla del palacio episcopal y en los del dormitorio canonical, levantados durante el s. XIV con este mismo tipo de acabados (Almuni 2007: 339-353). Una característica que nos permite diferenciar esta obra más tardía, sin embargo, son las habituales y abundantes marcas de cantero presentes en estos sillares -de módulo muy inferior a los andalusíes- inexistentes en el caso de las construcciones altomedievales.

\section{REFORMAS DEFENSIVAS PERIURBANAS: EL HIȘN DE AMPOSTA}

Situado a unos $12 \mathrm{~km}$ de Tortosa y sin que aparezca jamás en las detalladas descripciones que al-Idrīsī hace de este territorio, entre otras opiniones se ha propuesto que el nombre de Amposta provendría de un arcaísmo latino (imposita), atribuyendo tal denominación a la construcción de un castillo condal hacia finales del s. XI (OC: II, 185-186). De hecho, el lugar se documenta por primera vez de forma segura en enero de 1098, cuando el conde Ramon Berenguer III encomienda al conde de Pallars, Artau I, el castillo que pensaba establecer aquí (castrum quod disponit facere in loco vocato Amposta), junto con los castillos de Granyena y Tàrrega, prometiendo cederle, además, el castillo de la Suda de Tortosa y sus derechos con las mismas condiciones que el primero si conseguía obtener esta ciudad (ACB: 296).

De estas mismas condiciones descritas en el texto se desprende, sin embargo, que el castrum proyectado en Amposta hace referencia más al establecimiento de un distrito que no a la construcción de un edificio, pues se fragmentan en seis partes sus competencias, cuatro de las cuales se encomiendan en feudo a cambio de fidelidad, otra más en alodio o dominicatura, reservándose el conde de Barcelona la propiedad de la última. Fracasado este ambicioso proyecto, la ocupación feudal de Amposta debió ser contemporánea a la conquista de Tortosa en 1148 y se concedió definitivamente a la orden del Hospital. La inexistencia en cualquier caso de ninguna mención a este hiṣn en las fuentes árabes podría ser debido a su consideración como parte de la ciudad de Tortosa, a modo de bastión y puerta de entrada al curso de la vía fluvial del Ebro, o por tratarse de uno de los ḥuṣūn no identificados en las fuentes árabes. A pesar del territorio que posteriormente parece controlar, su suerte habría estado ligada constantemente a la de la ciudad, de aquí que las reformas califales que afectaron a la capital también tuviesen su reflejo en esta estratégica fortificación.

Emplazado en el núcleo antiguo de esta población y vigilando la desembocadura del río Ebro, justo antes del recrecimiento del delta fluvial, el castillo de Amposta ha 


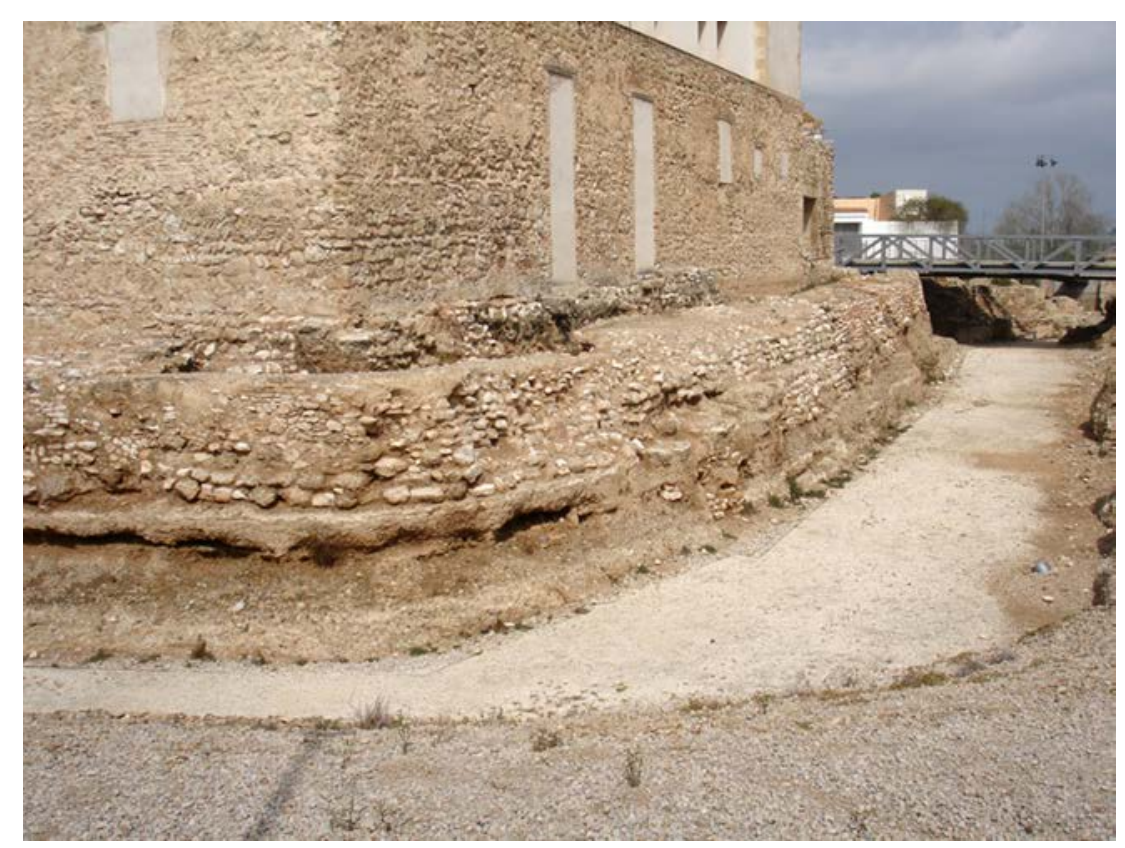

Fig. 5. Detalle del sistema de fosos y planta de la fortificación de Amposta (Maria Cinta Montañés y Àlex Ramos).

sido objeto de estudio arqueológico durante los últimos treinta años y debió ocupar una superficie aproximada de media hectárea. Con planta poligonal irregular, rodeado por un sistema de fosos y por el propio río, las sucesivas intervenciones arqueológicas se han centrado principalmente en los extremos occidental y meridional de un espacio que fue habitado en época ibérica y posteriormente durante el período andalusí, manteniéndose ocupado desde entonces. Estas características confieren a este emplazamiento un alto grado de complejidad y dificultad en la lectura de sus restos, que se presentan muy arrasados y alterados. Así, los materiales cerámicos de su fase antigua casi no conservan otras estructuras asociadas más allá de un fragmento de muro, si bien se atribuye a la etapa ibérica un conjunto de silos que fueron amortizados en época andalusí (Villalbí et al. 1994; 2007).

Es durante el período andalusí, en cualquier caso, cuando se diseña el trazado de las defensas fortificadas que afectan tanto al conjunto del área de fosos, con grandes canales en forma de $U$ que se bifurcan justo en el extremo noroccidental del conjunto, como en el núcleo del castillo propiamente dicho, que se organiza mediante murallas sucesivas y diversos bastiones. El funcionamiento del foso exterior, a pesar de su singularidad, no parece diferir en exceso respecto de otro ejemplo andalusí como es la fortificación de Calatrava la Vieja, donde se supone una aportación de aguas directamente desde el río o a través de un ingenio de elevación de agua, una cenia o noria, en caso de que su caudal disminuyese (Retuerce y Hervás 2004: 391-392; Hervás y Retuerce 2014: 220 225). Este sistema se verifica históricamente al acudir a diversos planos antiguos del castillo, como el de 1751, donde se puede observar perfectamente la integración completa entre este sistema perimetral y el río (Villalbí et al. 1994: fig. 7). Igual que el de Amposta, el foso del asentamiento fortificado castellano debió de planificarse en el momento de su fundación, a finales del s. VIII (Retuerce y Hervás 2000: 297), pues la elección de su emplazamiento ya tenía en cuenta esta especificidad. Desafortunadamente, con su excavación se comprobó que, a causa de la amplia cronología que alcanzaba y de la amortización del mismo hasta tiempos recientes, la detección de materiales de una primera fase inicial del recinto resultaba harto complicada (Villalbí et al. 1994: 191).

En cuanto al núcleo del castillo, éste presenta una doble muralla que incorpora un paso de ronda en su interior. El muro exterior presenta también restos de dos construcciones sucesivas, el trazado de las cuales se asienta sobre el límite del foso mediante una base ligeramente ataludada, construida con piedra y mortero y ajustada al recorrido del recorte. Por otra parte, el segundo muro presenta también una base construida con piedra y alzado de tapia, trazando lienzos rectos que discurren en paralelo a la barbacana. Entre ambos, el paso de ronda originalmente tendría una anchura 
aproximada de 1,40 m y en él se observan dos niveles andalusíes vinculados al refuerzo de las defensas exteriores (Villalbí et al. 2007: 4147). Respecto a la datación de este conjunto de doble muralla con paso de ronda hay quien considera que debe ser anterior al s. XI (Villalbí et al. 2005: 133), aunque otros autores la sitúan hacia mediados de este mismo siglo (Montañés 2007: 24). Cabe destacar, de todas maneras, que la excavación realizada en el extremo norte de la muralla recuperó ciertos materiales muy significativos, como un cántaro con asas retorcidas (Montañés y Ramón 1995), una tipología morfofuncional muy característica de los contextos alto-medievales en todo el territorio de Tortosa (Negre 2014).

Uno de los elementos más significativos de la fortificación, no obstante, lo constituyen los restos de la torre denominada de Sant Joan, construida con un magnifico aparejo de talla alargada dispuestos a soga y tizón, que presenta almohadillados en su cara externa y cuya altura debió ser muy superior según representa un antiguo grabado de Moulinier publicado por Laborde en el s. XIX (Villabí et al. 1994: fig. 10). Semidestruida por una industria contemporánea, su planta es rectangular y los dos muros conservados tienen un grosor de 2,5 m, presentando saeteras en posición central y unas dimensiones visibles de 11,75 por 9,2 $\mathrm{m}$ de lado. Sus sillares siguen módulos regulares, dispuestos en filas de 30 a $40 \mathrm{~cm}$ de altura, con bloques que oscilan entre 70 y $150 \mathrm{~cm}$ de largo, con una profundidad de $60 \mathrm{~cm}$.
Este bastión singular ocupa el ángulo noroccidental de la fortificación y custodia el inicio del dispositivo de fosos, y se insiere aquí mediante el acondicionamiento del suelo natural, con afectación de la muralla exterior que vino a reforzar en este punto (Villalbí et al. 2007: 415). Por eso y por no contar con menciones precisas anteriores al s. XV, se ha considerado de forma unánime que esta obra podría corresponder a finales de la Edad Media, una atribución que se fundamenta en el uso durante ese período de sillares almohadillados en otras obras de su entorno, como los descritos anteriormente para la obra gótica de la ciudad de Tortosa, desatendiendo en todo caso a las notables diferencias de módulo (Villalbí et al. 1994: 194). Por otro lado, los sillares almohadillados de la torre de Sant Joan no son los únicos presentes en el castillo de Amposta, localizándose también en otras defensas, como sucede a levante en algunos tramos de la muralla de la fachada fluvial, aunque en este punto pierden su disposición metódica. A pesar de su almohadillado característico, distinguimos aún que los módulos de talla y la disposición de estos últimos sillares son muy diferentes, y sin materiales arqueológicos asociados no pueden relacionarse con los de la torre.

Aunque definan formas y proporciones distintas, por su aparejo la torre de Sant Joan se asemejaría más bien a los basamentos ataludados de las torres de Castell Formós, también dispuestos sobre un foso, aunque en el caso

Fig. 6. Torre de Sant Joan.

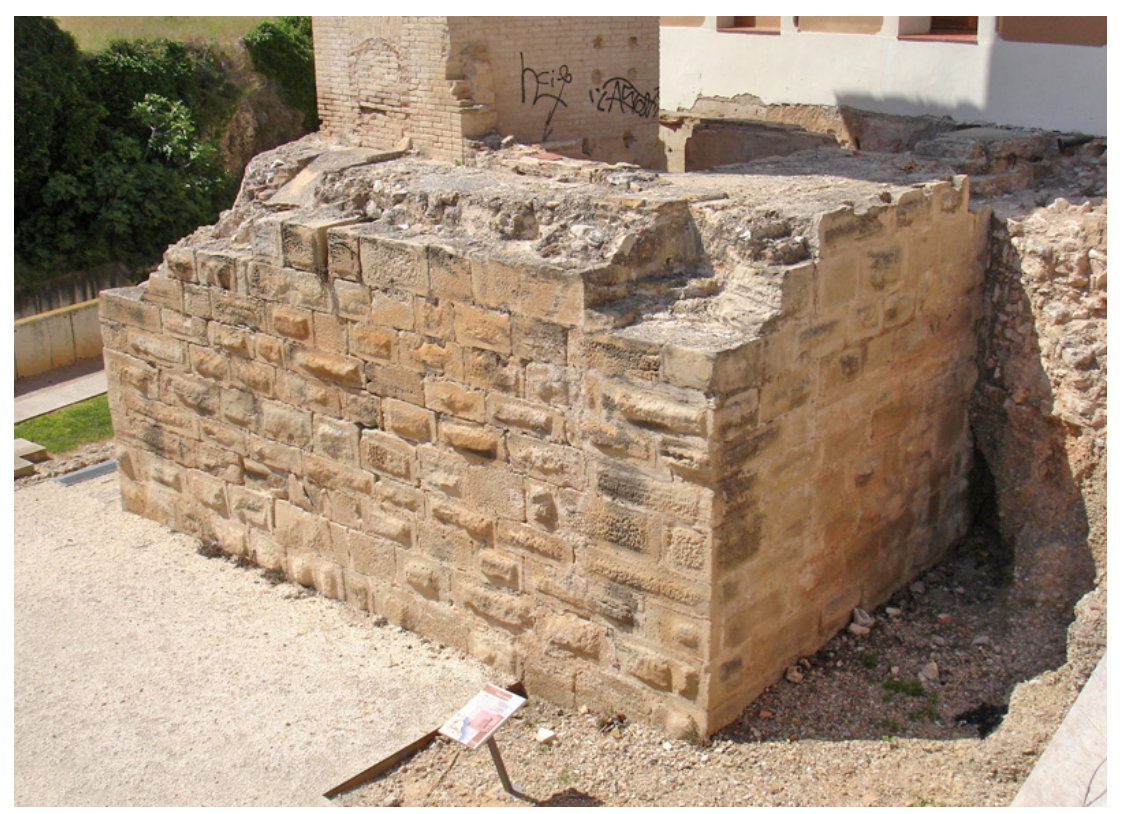


de Amposta se trataría de la remodelación de una defensa anterior y no de un diseño de conjunto, como en Balaguer. Por otra parte, la monumentalidad y regularidad de los módulos de los sillares almohadillados de Amposta sugieren que pueda tratarse de una iniciativa estatal, vinculada a la autoridad cordobesa y ejecutada por canteros de la región, tal y como ha sido observado para las obras urbanas (Martí y Negre 2014). Observamos, por otro lado, que desde inicios del Califato se emprende una ingente tarea de fortificación portuaria, como los casos señalados anteriormente de la torre de Tarifa o el arsenal de Algeciras, construcción esta última con bloques de tamaños similares a los presentes en la torre ebrense (Bravo et al. 2009: 133-134).

Por todo ello planteamos, a modo de conclusión, que la fundación del castillo de Amposta y de su dispositivo de fosos puede remontarse a un momento impreciso de la primera mitad del s. IX, probablemente durante su primer cuarto. A este momento correspondería la noticia escrita en el s. XIV por al-Himyarī (Al-Himyarī: 179), informada principalmente a partir de las obras de al-Rāzī (s. X) y al-Idrīsī (s. XII), sobre el asentamiento de un grupo de normandos (al-maŷūs) en la boca del río Ebro, en el lugar de al-Qabțīl. Según el autor magrebí, estos habrían excavado entorno de su campamento (al-saskar) un foso para protegerse. Resulta como mínimo remarcable que

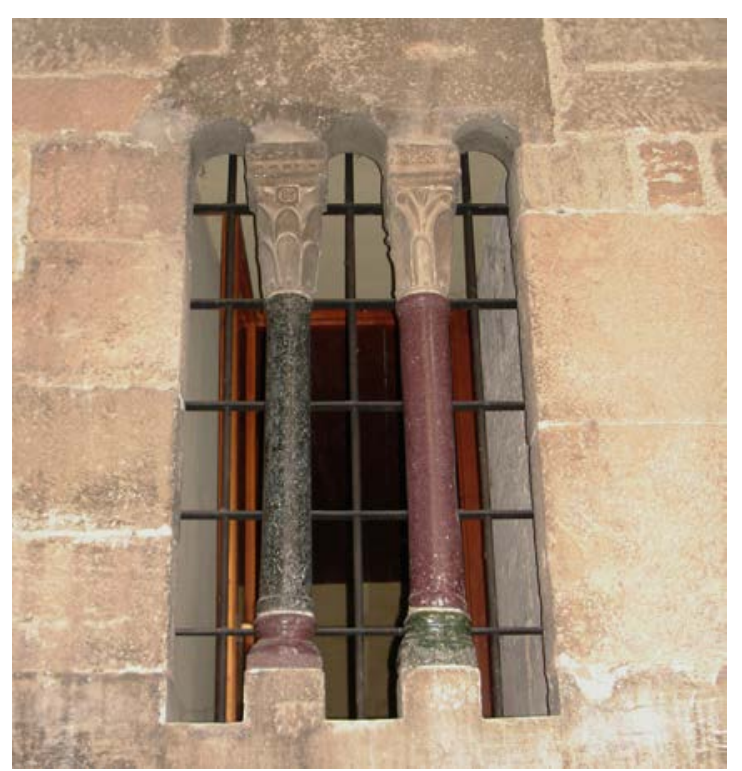

Fig. 7. Columnas del claustro probablemente pertenecientes al mih̆rāb califal de la mezquita aljama. mientras que no vuelve a mencionarse en las fuentes árabes este lugar, el hișn de Amposta, situado en la desembocadura del río, justo en el límite con las sedimentaciones deltaicas, dispone del único sistema de fosos documentado para este período en esta zona. Podría tal vez esta noticia relacionarse con un asentamiento momentáneo de los normandos en esta fortificación, que ya habría establecido este foso alrededor suyo y que éstos aprovecharían. En cualquier caso, el lugar fue profundamente remodelado ya durante el s. X, cuando se monumentalizó el conjunto mediante las obras especializadas de sillares almohadillados que acabamos de analizar.

\section{REFORMAS EN LA EDILICIA PÚBLICA: LA MEZQUITA ALJAMA Y LOS BAÑOS}

Una vez terminadas las principales reformas defensivas de la ciudad y su territorio, todo indica que la atención se volvió hacia los edificios de prestigio del interior del recinto urbano. En cuanto al oratorio principal, es alHimyarī quien precisa su construcción hacia el año 955956, fecha que debió constar en su lápida fundacional. La describe como un edificio de cinco naves con un amplio patio delantero de recepción (Al-Ḥimyarī: 151-153), el cual fue asignado después de la conquista cristiana a la nueva sede episcopal, que instaló aquí su primer centro de culto mientras tejía sus propias iniciativas constructivas que acabarían por aniquilarla bajo el propio desarrollo de las nuevas dependencias catedralicias (Almuni 2007: 258264). Del minucioso trabajo realizado por Almuni sobre la obra gótica del conjunto, parece que nada se haya conservado de la mezquita aljama de la ciudad, si bien se propone su ubicación en los alrededores del claustro. Es justamente en este espacio abierto donde se encuentran las únicas piezas que creemos que podrían asociarse a la construcción califal, dos pequeñas columnas, que actualmente forman parte de una ventana trigémina y que se localiza en el muro meridional del claustro, situadas allí durante la construcción del mismo durante el s. XIII (Almuni 2007: 296).

Hasta ahora fechadas tradicionalmente entre los ss. IV y $\mathrm{V}$ y adscritas a la obra de la sede visigoda (Arbeloa 2000: 54-56), se propone para estos elementos una cronología califal, considerando que habrían sido llevadas a Tortosa con la intención de formar parte del mihrāa $b$ de la mezquita aljama levantada en tiempos de 'Abd alRaḥmān al-Nāșir. Se trata de dos piezas lisas, cilíndricas 
y de dimensiones similares, una de pórfido rojo, probablemente egipcio, y la otra de calcárea verde, de origen desconocido, con las bases intercambiadas y coronadas con capiteles. El fuste de la columna de pórfido tiene una altura de $67,5 \mathrm{~cm}$ con ábaco y apófisis en la parte superior y toro en la inferior; la base de $11 \mathrm{~cm}$ de altura está compuesta por un plinto de sección cuadrada, toro, apófisis, escocia, apófisis y toro, siendo toda ella de calcárea verde, como el fuste de la otra columna. El capitel tiene 35,5 $\mathrm{cm}$ de altura. Fuste y capitel alcanzan una altura de 1,14 m. La segunda columna es de calcárea verde con base de pórfido rojo, presentando similares características a la primera columna, con una altura de $70 \mathrm{~cm}$ del fuste, 11 $\mathrm{cm}$ de plinto y $35 \mathrm{~cm}$ de capitel, sumando $1,16 \mathrm{~m}$ de altura el conjunto de la pieza. Los materiales utilizados para estas columnitas, ambos foráneos y llegados posiblemente a través de importaciones orientales, nos hacen proponer esta filiación entre las piezas en cuestión y las reformas califales del oratorio principal de la ciudad.

Cabe observar que, para formular esta hipótesis que desecha su presencia en la basílica tardo-antigua, hemos de acudir a casos paralelos de construcciones de este tipo dentro del ámbito peninsular durante el mismo período. Así, podemos observar como en Córdoba el califa alHakam al-Mustanșir ordenaría una reforma integral de la mezquita aljama (961-965) pocos años después de quedar terminada la de Tortosa, que sería llevada a cabo por su ministro (hâ̄ŷib) Ŷa'far ibn 'Abd al-Rahmmān, un personaje con una intensa participación en el programa de reformas que asimismo se llevó a cabo en la capital cordobesa. En la reforma de esta mezquita, Ŷa'far decidió conservar las cuatro columnas del miḥrāb emiral de 'Abd al-Raḥmān al-Awsaț, que quedaron integradas finalmente en el nuevo espacio sagrado del edificio califal (Ibn 'Idārī: 292-293). Se las describe como basas áticas, fustes, de brecha marmórea, dos de color verde muy intenso y los otros dos de rojo vivo (Gómez-Moreno 1963: 49), un esquema idéntico al tortosino, que debió inspirarse en el mihrāa capitalino.

Todo parece indicar que este modelo de columnas sobre las que descansaría el arco de entrada al mihrāb es un modelo ampliamente extendido en el $\mathrm{N}$ de África y el Mediterráneo Occidental, siendo quizás uno de sus primeros ejemplos, de inspiración oriental, el de la Gran Mezquita de Qayrawan (836), cuyo arco descansaba sobre columnas bizantinas también de pórfido (Al-Bakri: 57). Es la misma mezquita que sirvió de modelo también para el conjunto de columnas asociadas a arcos exentos como se advierte en la estructura de la mezquita emiral de Córdoba, que a posteriori se usó de nuevo en el Salón Oriental de Madīnat al-Zahrā' (Pavón 2004: III, 140). Así pues, parece que debemos su introducción en al-Andalus a la reforma de la mezquita capitalina llevada a cabo por 'Abd al-Raḥmān al-Awsaṭ en torno al 844 , momento al cual se atribuye también la introducción del miḥrāb-habitación en Córdoba en sustitución del más simple nicho que habría caracterizado este espacio con anterioridad (Pavón 2004: IV, 74-75). Es poco después de este momento cuando se documentan aún otros dos ejemplos claros, a finales de la década de los 60 del s. IX; un primero en la mezquita de Vera (Almería) con dos columnas bajo el arco y otras cinco en el interior del espacio sagrado, todas de mármol veteado blanco y negro y otro en la Mezquita de Ibn Țūlūn (El Cairo) con cuatro columnas de mármol con capiteles bizantinos (Hoag 1976: 60).

Podrían estas columnas estar en relación con las portadas honoríficas o laudatorias de esquema tardoantiguo y paleocristiano, de las cuales expoliarían en muchos casos estos elementos, tal y como las fuentes árabes parecen indicar en los casos mencionados de Qayrawan e Ibn Țūlūn. Un modelo que el arte islámico incorporaría posiblemente a través del contacto con la edilicia bizantina para aplicar a partir principalmente del s. IX a sus estructuras de prestigio más simbólicas. Es el caso de las mezquitas ya citadas así como los ejemplos de los rubūt tunecinos de Monastir y Susa (Pavón 2009). En el caso peninsular todo parece indicar, no obstante, que este modelo mostraría su máxima expansión a partir del califato, cuando se emprenderían una serie de iniciativas con la finalidad de difundir el nuevo Estado islámico a través de la construcción o reforma de grandes oratorios en las principales ciudades de al-Andalus a semejanza del capitalino, como podrían ser la mezquita aljama de Almería (Cressier 1992: 269) o la de Tortosa, tal y como defendemos en este texto.

Este tipo de modelo de columnas coronadas por capiteles, en algunos casos imitando incluso la alternancia de colores entre ellas, es utilizado de forma generalizada en la edilicia de prestigio califal, tanto civil como religiosa. Así, las columnitas del miḥrāb de Córdoba parecen haber servido como base para la reforma de la nave central de la sala de oración de la mezquita, con decenas de columnas de mármol y jaspe talladas ex profeso en tonos rojos y azules oscuros con capiteles con motivos florales. Podemos ver este mismo motivo repetido de nuevo en 


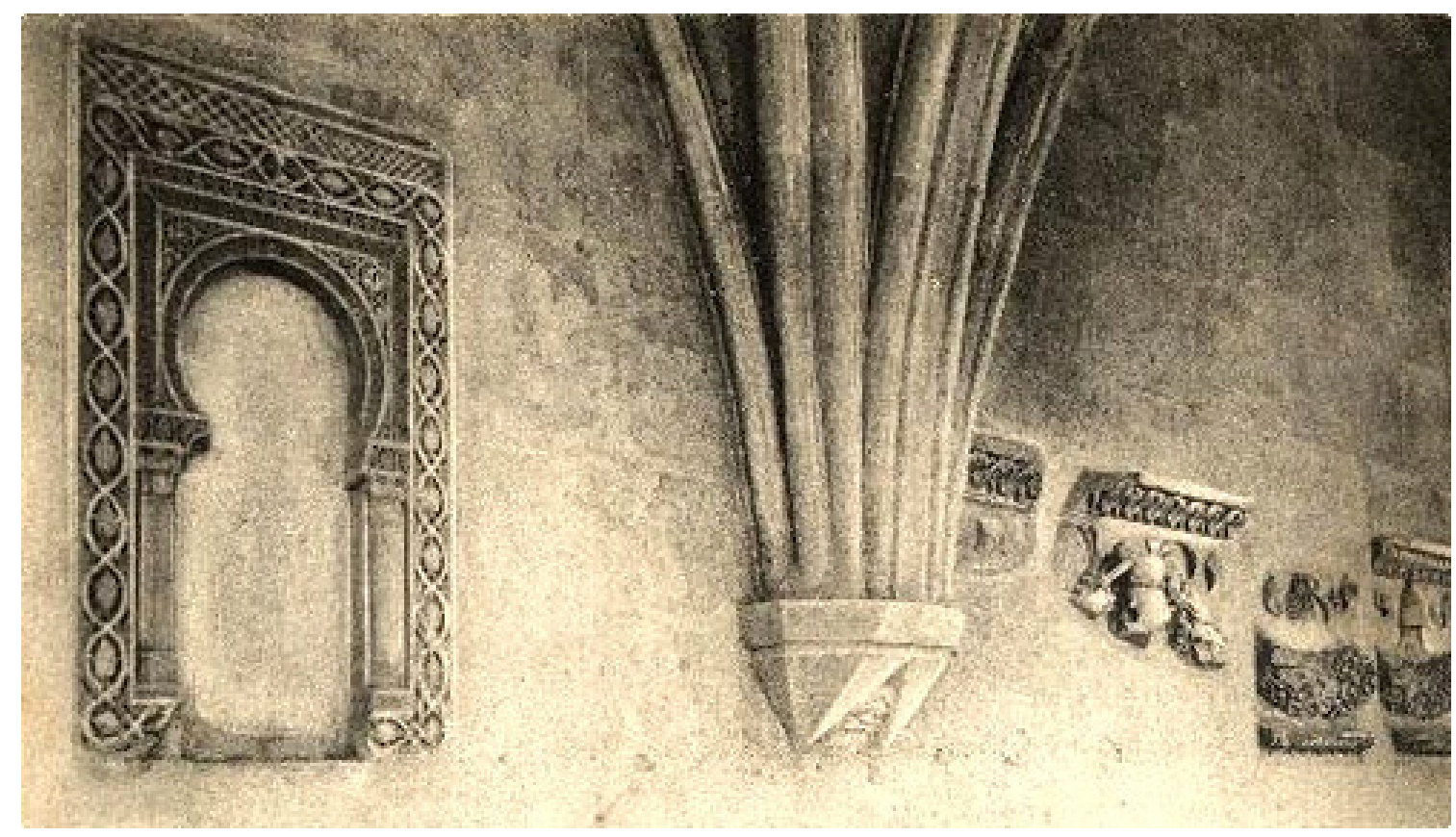

Fig. 8. El, erróneamente, llamado mihrāb de Tarragona, proveniente probablemente de los baños califales de Tortosa (Aceña, 1995).

diversos ámbitos de la ciudad palatina de Madīnat alZahrā', como las diversas series de columnas del Salón Rico, construidas contemporáneamente (953-957) a la mezquita aljama de Tortosa, tal y como muestra su epigrafía. Aunque los materiales tortosinos no parecen guardar relación con los talleres cordobeses, su presencia en el entorno del claustro sugiere que pudieron imitar aquel diseño, formando parte del programa decorativo de la desaparecida mezquita califal (Martí y Negre 2014). Se atribuye, por tanto, a los promotores de este programa el envío de estos materiales de prestigio hacia Tortosa, probablemente desde la propia capital andalusí; un ejemplo que, como veremos, no es el único.

Podemos ilustrar esta misma dinámica si retornamos a la figura de $\hat{Y}$ a'far ibn 'Abd al-Raḥmān y a las influencias cordobesas en las reformas califales llevadas a cabo en la ciudad de Tortosa, en este caso centrando la atención en los baños de la ciudad. De los cuatro con que debió contar la ciudad según las descripciones árabes (Al-Himyarī: 151-153) pensamos que al menos uno de ellos se debió a esta misma iniciativa califal, si resulta cierta, como parece, la atribución que a continuación planteamos. A nuestro parecer, debe proceder de Tortosa el erróneamente llamado mihrāb de Tarragona, un arco de herradura tallado y biselado en una sola pieza de alabastro de 129,5x75,5 cm, con restos de policromía, la relación del cual con Madīnat al-Zahrā’ resulta incuestionable. El mencionado arco viene enmarcado por un arrabá con una inscripción donde se invoca la bendición divina para el califa 'Abd al-Raḥmān al-Nāṣir por la obra realizada bajo la dirección de su fatà y mawlà Ŷa'far, entre los años 960-961. De este personaje, como hemos visto, tenemos abundante documentación que nos detalla su intensa actividad en la residencia califal y en la capital aporta paralelos decorativos comunes que ahora sirven para analizar con más detenimiento esta pieza en concreto.

Conservada hoy en día en el Museu Diocesà de Tarragona, esta pieza fue atribuida primero a una ventana del baño de 'Abd al-Raḥmān al-Nāṣir, en la terraza superior de Madīnat al-Zahrā' (Aceña 1995) y posteriormente a la mezquita de Tortosa (Miravall 1999). Por nuestra parte, intuimos que la solución al origen de este elemento se encuentra en un término medio entre ambas propuestas, pues analizando las obras de la ciudad palatina, en especial los arcos decorativos del baño del califa y de la Vivienda de la Alberca, parece indiscutible tanto su procedencia cordobesa como la vinculación a un mismo programa decorativo de época califal finalizado en torno 
al año 961 y que tiene a Ŷa'far como su máximo valedor (Vallejo 2013: 330). Demostrada su relación con este entorno, cabe suponer que, como sucede con los capiteles califales (Cressier 2004), esta pieza pudo ser producida en unos talleres centralizados y de aquí remitida a Tortosa para su instalación en los baños que, por la fecha de la inscripción, debieron terminarse alrededor del año 961. A modo de corolario, la que parece ser la hipótesis más plausible sobre el traslado definitivo de esta talla a la catedral de Tarragona nos remite ya al s. XVI (Miravall 1999).

\section{CONCLUSIONES}

La intervención del Estado cordobés en la ciudad de Tortosa durante el período de paz mantenido durante las décadas centrales del s. X (940-974) queda patente en las fuentes árabes y en los indicios arqueológicos y monumentales, donde se consigna la reorganización de sus murallas y la construcción de su arsenal. Pero también existen serios indicios de que la reconstrucción de la mezquita aljama y de sus baños principales se hicieron a imitación de modelos califales, incorporando incluso elementos, hoy dispersos, procedentes de los talleres cordobeses. Estos elementos, junto a las importantes transformaciones llevadas a cabo en la fortificación de Amposta, componen el conjunto de reformas con las que el califa dotó a la ciudad de Tortosa con el objetivo de reforzar este enclave fronterizo. A pesar de la creación de una densa red de hușūn en el conjunto del territorio tortosino con funciones militares pero también administrativas, en el caso de la región de control más directo desde la ciudad la Suda y el hiṣn de Amposta se muestran suficientes para ejercer el control de esta área. No obstante, todo parece indicar que estas dos posiciones debieron valerse de un conjunto de atalayas, con las que mantendrían un sistema de vigilancia que recorrería el valle del Ebro, como mínimo entre la fortificación de Miravet (Ribera d'Ebre) y la de la desembocadura del río (Martí y Negre 2014).

Sin que a partir de ese momento se perciba un incremento en el nombre de castillos sino, más bien, un crecimiento del dominio urbano sobre el ámbito rural, en época taifa y almorávide se desarrollarían actuaciones de carácter palatino al tiempo que se emprendían notables mejoras en las fortificaciones más avanzadas sobre la frontera. Ahora sujetos inequívocamente al gobierno de la ciudad de Tortosa, estos hușūn reforzarían sus muros o desarrollarían nuevas estrategias defensivas, como pudieron ser la barbacana y los pasos de ronda que se detectan en algunos de los casos excavados. Por otro lado, es en este momento cuando empiezan a desarrollarse otras soluciones de control y vigilancia, como la cesión de un conjunto de torres de planta circular en el ámbito rural, en funcionamiento bajo el control de la ciudad probablemente desde el s. IX, a unas élites locales a cambio, tal vez, de prestaciones militares. Son estas algunas de las almunias descritas por las fuentes latinas posteriormente a la conquista, como las de l'Aldea, Burjassénia o l'Antic, inscritas ya en unas dinámicas de defensa y explotación del territorio muy diferentes a las analizadas para el período presentado en este texto.

JoAn Negre Pérez Ramon Martí Castelló Departament de Ciències de l'Antiguitat i de l'Edat Mitjana Universitat Autònoma de Barcelona negreperez@gmail.com ramon.marti@uab.cat

\section{AGRADECIMIENTOS}

Esta investigación se ha desarrollado a partir de un proyecto específico de prospección arqueológica, financiado por la Direcció General del Patrimoni Cultural de la Generalitat de Catalunya (IA2010-56400) y ha sido amparado en todo momento por el proyecto marco "Organización fiscal y ocupación del territorio durante la Alta Edad Media" (HAR2009-07874), dirigido por el Dr. Ramon Martí Castelló (UAB, Grup de Recerca OCORDE - 2009SGR727). Así mismo, este texto se ha beneficiado de los comentarios y aportaciones desinteresadas del doctor Julio Navarro Palazón, de la Escuela de Estudios Árabes (CSIC).

\section{FUENTES}

ACB. Arxiu Comtal de Barcelona. I. Baiges et al. (eds.) (2010): Els pergamins de l'Arxiu Comtal de Barcelona, de Ramon Berenguer II a Ramon Berenguer IV, Barcelona.

Al-Bakrī. Kitāb al-Mughrib fì dhikr bilād Ifrīqūyah wa-al-Maghrib: wa-huwa juz' min ajzā' al-kitāb al-ma 'rūf bi-al-Masālik wa-al-mamālik. M.G. de Slane (tr.) (1859): Description de l'Afrique Septentrionale, Paris.

Al-Himyarī. Al-Rawḍ al-mi'țār fì-jabar al-aqțār. I. 'Abbās (ed.). Beirut: Maktaba Lubnān, 1984 i E. Levi-Provençal (tad. parc.). La Peninsule iberique au Moyen age d'après le Kitab al-Rawd al-mi'tār d'Ibn Abd al-Mun'im al-Himyarī. Leiden: E.J. Brill, 1938.

CPFC. Cartas de Población y Franquícia de Cataluña. J.M. Font Rius (ed.), Barcelona, 1969. 
DCT. Diplomatari de la Catedral de Tortosa. A. Virgili (ed.). Barcelona, 1997.

Ibn al-Abbār. al-Takmila li-kitāb al-Șila. F Codera (ed.) (18871889): Complementum libri Assila. Madrid, volums 5 i 6; M. Alarcón y A. González (eds.) (1915): Apéndice a la edición de Codera de la Tecmila de Aben Al-Abbar, Miscelánea de Estudios y Textos Árabes. Madrid, 147-690.

Ibn al-Jațīb. Al-Ihāṭa fì ajbār Garnāṭa. M. 'Inān (ed.) (1978): Maktabat al-Janji, El Caire. D. Bramon (trad. parc.) (2000): De quan érem o no musulmans. Textos del 713 al 1010, Barcelona.

Ibn al-Qūțiyya. Ta'rīj iftitāh al-Andalus. J. Ribera (trad.) (1926): Historia de la conquista de España de Abenalcotía el Cordobés, Madrid.

Ibn Hayyān. Al-Muqtabis. P. Chalmeta; F. Corriente; M. Subḥ (eds.) (1979): Al-Muqtabas (Al-ŶYu' al-jāmis), Madrid. D. Bramon (trad. parc.) (2000): De quan érem o no musulmans. Textos del 713 al 1010, Barcelona.

Ibn Hayyān 2. Al-Muqtabis fì ajbār balad al-Andalus. 'A. 'A. alHaŷŷ̄ (ed.) 1965, Beirut; E. García (tr.) (1967): El Califato de Córdoba en el "Muqtabis" de Ibn Hayyān. Anales palatinos del califa de Córdoba al-Hakam II, por '⿳亠̄sā Ibn Ahmad al-Rāzī (360-364 H./971-975 J.C.), Madrid. D. Bramon (trad. parc.) (2000): De quan érem o no musulmans. Textos del 713 al 1010, Barcelona.

Ibn 'Idārī. Kitāb al-Bayān al-mugrib fì ajbār mulūk al-Andalus wal-Magrib. R. Dozy (ed.) (1848-1851): Histoire de l'Afrique du Nord et de l'Espagne musulmane, Leiden; E. Fagnan (tr.) (1901-1904): Histoire de l'Afrique et de l'Espagne intitulée al-Bayano 'l-Maghrib, Argel.

Ibn Jaldūn. Kitāb al-'ibar. R. Dozy (ed.) (1881): Recherces sur l'Histoire et la Littérature de l'Espagne pendant le Moyen Age, Leiden. D. Bramon (trad. parc.) (2000): De quan érem o no musulmans. Textos del 713 al 1010, Barcelona.

OC. Onomastico Cataloniae. J. Coromines (ed.) (1989-1997): Onomasticon Cataloniae: els noms de lloc i noms de persona de totes les terres de llengua catalana. 8 volúmenes, Barcelona.

TTE. J. Pagarolas (ed.) (1999): Els Templers de les Terres de l'Ebre. 2 volúmenes, Tarragona.

\section{BIBLIOGRAFÍA}

ACEÑA, R. (1995): El mihrab hispano-musulmà, Catalunya Romànica (A. Pladevall, dir.), vol. XXI, Barcelona, 196-198.

ALMUNI, V. (2007): La catedral de Tortosa als segles del gòtic, Barcelona.

ARBELOA, J. (2000): Dertosa a l'Antiguitat Tardana. Consideracions sobre els espais culturals, Nous Col-loquis 4, 45-71.

BALLESTÍN, X. (1999): De la instauració de la hilāfa dels Banū Marwān -317 H./929 d.C.- als Mulūk aț-Tawā'if, Musulmans i Catalunya (M. Barceló, ed.), Barcelona, 79-94.
BARRASETA, E.; CASANOVAS, B. (1988): Memòria de la prospecció arqueològica efectuada al solar del c/ Taules Velles $n^{\circ} 4$, de la ciutat de Tortosa, Memoria de excavación: Servei d'Arqueologia, Direcció General del Patrimoni Cultural

BRAMON, D. (2000): De quan érem o no musulmans. Textos del 713 al 1010, Barcelona.

BRAVO, S.; VILA, M.; TRINIDAD, D.; DORADO, R. (2009): Resultados de la actividad arqueológica preventiva en Avenida de la Marina, esquina calles Segismundo Moret y Teniente Riera de Algeciras (Cádiz), Caetaria 7, 131-156.

CRESSIER, P. (1992): La decoración califal del Mihrab de la mezquita mayor de Almería: nuevos descubrimientos, Estudios de arqueología medieval en Almería (P. Cressier, coord.), Almería, 265-285.

CRESSIER, P. (2004): Historias de capiteles. ¿Hubo talleres califales provinciales?, Cuadernos de Madīnat al-Zahrā' 5, 355-375.

CURTO, A. (1997): Castell de la Suda (o de Sant Joan), Catalunya Romànica (A. Pladevall, dir.), vol. XXVI, Barcelona, 114-117.

CURTO, A. (1999): Topografia del call jueu de Tortosa, Recerca 3 , 9-24.

CURTO, A.; LORIENTE, A.; MARTÍNEZ, CH.; ROS, E. (1986): Els nivells islàmics en l'excavació en la plaça de Ntra. Sra. de la Cinta o de l'Olivera de la ciutat de Tortosa (Tarragona), I Congreso de Arqueología Medieval Española, Zaragoza: AEAM, 99-112.

DILOLI, J.; BEA, D.; FERRÉ, R.; GONZÁLEZ, A.; NAVARRO, S.; SARDÀ, S.; VILÀ, J. (2008): Intervencions arqueològiques a Tortosa en el marc del projecte "Anàlisi de l'Evolució urbana de la ciutat de Tortosa des de la seva fundació fins a l'Alta Edat Mitjana". Anys 2003-2008, Butlletí Arqueològic de la Reial Societat Arqueològica Tarraconense 30, 151-199.

DILOLI, J.; FERRÉ, R.; JÀRREGA, R.; VILÀ, J. (2012): Darreres novetats sobre la Tortosa romana. Intervencions arqueològiques del GRESEPIA (URV) entre els anys 2006 i 2011 a la ciutat, Auriga. Revista de divulgació i debat del món clàssic 63, 36-39.

GARCÍA, J.E.; GIRALT, J.; LORIENTE, A.; MARTÍNEZ, J. (1998): La gènesi dels espais urbans andalusins (segles VIII-X). Tortosa, Lleida i Balaguer, L'Islam i Catalunya, Barcelona, 137-165.

GIBERT, J. (2011): L'Alta Edat Mitjana a la Catalunya Central (segles VI-VII). Estudi històric i arqueològic de la conca mitjana del riu Llobregat, Barcelona.

GIRALT, J. (1994): Castell Formós, Catalunya Romànica (A. Pladevall, dir.), vol. XVII, Barcelona, 225-238.

GÓMEZ-MORENO, M. (1951): El arte árabe español hasta los almohades, Ars Hispaniae: Historia Universal del Arte Hispánico, vol. 3, Madrid.

GURRIARÁN, P. (2001): Arquitectura y técnicas constructivas califales en el castillo de Tarifa, Almoraima 25, 159-180. 
Urbanismo en la Marca Oriental de al-Andalus durante el Califato (940-974): el ejemplo de Madīna Țurțuša a través de las fuentes ARQUEOLÓGICAS Y ESCRITAS

GURRIARÁN, P. (2004): Hacia una construcción del poder. Las prácticas edilicias en la periferia andalusí durante el Califato, Cuadernos de Madīnat al-Zahrā' 5, 297-325.

HERVÁS, M.A.; RETUERCE, M. (2014): Usos hidráulicos en el Alto Guadiana en la Edad Media: Calatrava la Vieja, Las Tablas y los Ojos del Guadiana: agua, paisaje y gente (M. Mejías, ed.), Madrid, 107-146.

HITA, J. M.; SUÁREZ, J.; VILLADA, F. (2008): Ceuta, puerta de al-Andalus. Una relectura de la Historia de Ceuta desde la conquista árabe hasta la fitna a partir de los datos arqueológicos, Cuadernos de Madīnat al-Zahrā' 6, 11-52.

HOAG, J. (1976): Arquitectura islámica, Madrid.

LORIENTE, A.; GIL, I.; PAYÀ, X. (1997): Un exemple de model urbà andalusí: Medina Larida. L'aportació de l'arqueologia urbana al món àrab, Revista d'Arqueologia de Ponent 7, 77-106.

MANZANO, E. (1991): La frontera de al-Andalus en época de los Omeyas, Madrid.

MARTÍ, R. (1992): La primera expansió comtal a ponent de Llobregat, Catalunya Romànica (A. Pladevall, dir.), Barcelona, 28-35.

MARTÍ, R. (2008): Fars de l'Islam. Antigues alimares d'al-Andalus, Barcelona.

MARTÍ, R.; NEGRE, J. (2014): Fortificaciones y edilicia de prestigio en el extremo oriental de la Marca Superior: Tortosa y su entorno, La ciutat medieval i Arqueologia. VI Curs Internacional d'Arqueologia Medieval (F. Sabaté y J. Brufal, dirs.), Lleida, 219-240.

MIRAVALL, R. (1999): Madina Turtuxa. Introducció a la Tortosa islàmica, Tortosa.

MONTAÑÉS, M. C.; RAMON, M. J. (1995): Memòria de l'excavació $i$ seguiment de les obres d'acondicionament del Castell d'Amposta (Montsià), Memòria d'Excavació: Servei d'Arqueologia, Direcció General del Patrimoni Cultural.

MONTAÑÉS, M. C. (2007): El procés de fortificació andalusina a les Terres de l'Ebre, Recerca 11, 11-42.

NEGRE, J. (2013): De Dertosa a Tortosa. L'extrem oriental d'alTagr al-A'là en el context del procés d'islamització d'alAndalus, Barcelona.

NEGRE, J. (2013b): Evolució de la xarxa viària del territori de Tortosa entre l'Antiguitat i l'Edat Mitjana, Quaderns de Prehistòria i Arqueologia de Castelló 31, 209-228.
NEGRE, J. (2014): La cerámica altomedieval de Tortosa (siglos VII-X). Una primera clasificación y análisis interpretativo, Arqueología y Territorio Medieval 21, 39-67.

NEGRE, J. (2015): Origen y desarrollo de la huerta de Tortosa (siglos IV-XII). El proceso de formación de una macro-espacio irrigado en el levante peninsular, Historia Agraria (en prensa).

PAVÓN, B. (2004): Tratado de Arquitectura Hispanomusulmana, 4 volúmenes, Madrid.

PAVÓN, B. (2009): Mihrab. Nicho, hornacina con columnas y concha en la arquitectura del islam occidental (Primera parte), Trabajo de investigación inédito, <http://www.basiliopavonmaldonado.es/documentos/mihrab_nicho.pdf $>$ (consulta 17-IV-2015).

RETUERCE, M.; HERVÁS, M. A. (2000): Calatrava la Vieja, capital islámica de la región, El patrimonio arqueológico de Ciudad Real. Métodos de trabajo y actuaciones más recientes (L. de Benítez, coord.), Valdepeñas, 297-322.

RETUERCE, M.; HERVÁS, M. A. (2004): Excavaciones arqueológicas en Calatrava la Vieja. Planteamientos y principales resultados, Investigaciones arqueológicas en Castilla-La Mancha 1996-2002, Toledo, 381-393.

SÉNAC, P. (2010): Linajes muladíes, juristas y fortificaciones en la Marca Superior de al-Andalus (siglos VIII-X), La Carisa y La Mesa. Causas políticas y militares del origen del Reino de Asturias, Oviedo, 234-247.

YZQUIERDO, P. (1998): Làpida fundacional de les drassanes de Tortosa, L'Islam i Catalunya, Barcelona, 47-48.

VALLEJO, A. (2013): El Alcázar de Madīnat al-Zahrā: permanencia y procesos de cambio, Anales de Historia del Arte 22, 325-344.

VILLALBÍ, M. M.; FORCADELL, T.; ALMUNI, V. (2005): El poblament andalusí al riu Sénia, Recerca 9, 1221-167.

VILLALBÍ, M. M.; FORCADELL, T.; ARTIGUES, P. LL. (1994): El castell d'Amposta. Nota preliminar, Quaderns d'Història Tarraconense 13, 185-207.

VILLALBÍ, M. M.; FORCADELL, T.; MONTAÑÉS, M. C.; RAMON, M. J. (2007): El castell d'Amposta: ordenació urbanística $i$ intervencions arqueològiques (Amposta, Montsià), Jornades d'Arqueologia 1999: comarques de Tarragona (1993-1999), Barcelona, 411-421 